\title{
Ciprofloxacin-resistant Campylobacter in broiler chicken in Canada
}

\author{
Agunos $A^{1^{\star}}$, Léger $D F^{1}$, Avery $B P^{1}$, Parmley $E J^{1}$, Deckert $A E^{1}$, Carson $C A^{1}$, Reid-Smith $\mathrm{RJ}^{1}$, \\ Irwin $\mathbf{R} \mathbf{J}^{1}$ \\ ${ }^{1}$ Laboratory for Foodborne Zoonoses, Public Health Agency of Canada, Guelph, ON \\ *Corresponding author: agnes.agunos@phac-aspc.gc.ca
}

\begin{abstract}
This case study outlines the patterns of ciprofloxacin resistance in Campylobacter isolated from retail chicken meat in Canada. Campylobacter is the third most common cause of foodborne enteric illness in Canada; it usually causes a self-limited illness, but in some cases antimicrobials may be indicated. Ciprofloxacin (a fluoroquinolone) is an antimicrobial used to treat a number of infections in humans; other fluoroquinolones are used both therapeutically and prophylactically in livestock animals, including broiler chickens. The Canadian Integrated Program for Antimicrobial Resistance Surveillance (CIPARS) has been testing retail chicken meat samples across Canada for the presence of Campylobacter and for resistant strains since 2003. At the end of 2010, CIPARS documented that retail chicken meat samples in Canada contaminated with Campylobacter ranged from $36 \%$ in the Maritimes to $42 \%$ in British Columbia. Furthermore, levels of ciprofloxacin-resistant Campylobacter varied across the country, with higher percentages in British Columbia (17\% in 2010) and Saskatchewan (11\%), in comparison with lower percentages in Ontario (5\%), Québec (2\%, and the Maritimes (4\%). In 2011 and 2012, resistance declined in British Columbia and Saskatchewan, but began to rise in Québec and Ontario. Recently, the Canadian poultry industry developed a policy to eliminate the preventive use of third generation cephalosporins and fluoroquinolones in broiler chickens (meat chickens) and broiler breeder chickens (chickens that produce the eggs that will become the broilers). CIPARS will continue to monitor trends in antimicrobial use and resistance following this industry intervention. By following good food preparation and hygiene practices, Canadians can reduce the risks of developing a Campylobacter infection (resistant or susceptible) from retail chicken.
\end{abstract}

\section{Introduction}

Antimicrobials have been commonly used in treating a multitude of infectious diseases and health challenges present in both humans and animals. This case study outlines the patterns of ciprofloxacin resistance in Campylobacter isolated from retail chicken meat in Canada, explores its potential implication to human health and identifies what is being done to address it. It is a story of how Canada's "farm-tofork" surveillance system, the Canadian Integrated Program for Antimicrobial Resistance Surveillance (CIPARS), detected this resistance pattern and tracked it as it emerged across the country. We also identify the impact of this information on the use of antimicrobial drugs in the Canadian poultry industry and what further steps are being taken to better understand and decrease this potential threat to both human and animal health.

\section{Campylobacter}

Recent estimates showed that approximately $90 \%$ of an estimated 1.6 million cases of domestically acquired foodborne illnesses in Canada are caused by four pathogens: Norovirus, Clostridium perfringens, Campylobacter, and non-typhoidal Salmonella $(1,2)$. The majority of Campylobacter infections are usually self-limiting, causing diarrhea, abdominal cramping, fever, headache, and myalgia.

Campylobacter infections are thought to be acquired mainly through consumption of contaminated food products, with a smaller proportion of cases caused by direct contact with farm animals, pets, and 
contaminated recreational waters. Case control studies have identified a significant association between human campylobacteriosis and consumption of raw or undercooked poultry (3).

Treatment with antimicrobials is generally not required for uncomplicated cases, but may be necessary for treating vulnerable patients or those with severe, prolonged or systemic infections. In the event treatment is needed, the macrolide drugs erythromycin or azithromycin are recommended, with ciprofloxacin as an alternative drug (4). However, in a study of antimicrobial use and resistance in two health units in Ontario, 45 of the 138 human cases of campylobacteriosis used ciprofloxacin (5).

\section{Ciprofloxacin}

Ciprofloxacin is a fluoroquinolone antimicrobial commonly used in humans for the treatment of respiratory, urinary, skin, and bone/joint infections, as well as some cases of gastroenteritis in adults (6). Fluoroquinolones are considered "critically" or "very" important to human medicine (Category I) by the World Health Organization (7) and Health Canada's Veterinary Drugs Directorate (8).

Fluoroquinolones are used only for rare or sporadic bacterial disease outbreaks in chickens or in treating severe infections where commonly used antimicrobials proved ineffective (i.e., an increasing number of sick and/or dead birds noted in the flock despite antimicrobial use) (9). In Canada, enrofloxacin is licensed only for use in cattle, pigs, dogs, and cats, and danofloxacin is licensed only for cattle. These fluoroquinolone antimicrobials are not approved for use in poultry. According to Health Canada's Veterinary Drugs Directorate, this class of antimicrobial should not be used for mass medication purposes (i.e., to treat an entire flock or herd of animals) in an extra-label manner (i.e., in a manner that is not in accordance with the label or package insert) (10).

\section{Antimicrobial resistance surveillance}

The Public Health Agency of Canada coordinates CIPARS, a surveillance system that monitors antimicrobial use in humans and animals as well as antimicrobial resistance (AMR) in select bacteria from humans, animals and food (11). The agri-food component of this Program consists of surveillance through sentinel farms providing herd- or flock-level data on antimicrobial use and AMR; abattoir (slaughter plant) surveillance, providing national representative AMR data for bacteria isolated from animals as they enter the food supply; and retail surveillance, providing data on AMR for bacteria found in raw meat purchased at grocery stores reflecting consumer exposure to antimicrobial resistant bacteria in food. Quantities of antimicrobials distributed for sale for use in animals in Canada are also provided to CIPARS by the Canadian Animal Health Institute. Bacteria of interest are Salmonella, generic Escherichia coli, and Campylobacter.

\section{Detection of ciprofloxacin-resistant Campylobacter in retail chicken samples}

CIPARS has been testing retail chicken samples across Canada for the presence of Campylobacter since 2003, starting with Ontario and Québec and in additional provinces in more recent years. By the end of 2010, the percentage of retail chicken samples found to be contaminated with Campylobacter ranged from $21 \%$ in Québec to $42 \%$ in British Columbia (12).

Between 2005 and 2010, CIPARS observed an increase in the prevalence of ciprofloxacin resistance among the Campylobacter recovered from retail chicken meat. In particular, significant differences in the provincial prevalence of resistance were identified; resistance was observed to be rising in British Columbia (4\% in 2007 to 17\% in 2010) and Saskatchewan (6\% in 2005 to $11 \%$ in 2010), while remaining relatively low and stable among retail chicken isolates collected in Ontario (4\% in 2003 to $5 \%$ in 2010), Québec (3\% in 2003 to $2 \%$ in 2010), and the Maritimes (0\% in 2008 to $4 \%$ in 2010 (12).

Several communication strategies were used to notify public and veterinary health stakeholders of these findings. In the summer of 2010, the Ministries of Health and Agriculture in British Columbia and 
Saskatchewan were notified and poultry veterinarians were consulted. In the summer of 2011 , this issue was raised through a CIPARS Surveillance Bulletin (13) to inform the Canadian poultry industry, other commodity and veterinary organizations, and public health stakeholders. In the summer of 2013, a meeting was organized with poultry industry stakeholders to provide an update on these findings. During the CIPARS national multi-commodity stakeholder meeting in the fall of 2013 , this issue was further highlighted and more recent data presented.

CIPARS continues to monitor this issue through the farm, abattoir, and retail surveillance components and continues to see changes in the levels of ciprofloxacin resistance across the country. In 2012, both British Columbia and Saskatchewan showed decreasing levels of ciprofloxacin resistance in Campylobacter from retail chicken since the original notifications, with prevalences of $8 \%$ and $5 \%$, respectively. However, in 2012, increased resistance was found in areas where resistance had previously been rare. In Ontario, for example, resistance increased from 6\% in 2011 to $16 \%$ in 2012, while in Québec resistance increased from $0 \%$ in 2011 to 3\% in 2012 (14). This observation was confirmed by CIPARS abattoir surveillance data where a similar trend in ciprofloxacin resistance was noted among chicken Campylobacter isolates.

\section{Assessment and public health action}

Ciprofloxacin-resistant Campylobacter from retail chicken in Canada has become more widespread over the last few years (2011 and 2012) (14), although the extent and the trends vary according to region. The drivers of the emergence of resistant Campylobacter in retail chicken samples are unknown at this time, but the extra-label use of fluoroquinolones in broilers, broiler breeders, and imported hatching eggs and chicks have been hypothesized as a contributing factor (12).

Other factors may be at play here however. The literature suggests that on-farm sources and operational factors could contribute to the spread of antimicrobial resistant Campylobacter. A systematic review of the literature suggests that antimicrobial resistant Campylobacter may be disseminated within a flock through the drinking water line and could spread across the farm through farm workers (via contaminated footwear) (15). Campylobacter has been reported to be spread by chicken catching crews that travel from farm to farm and then onto slaughter plants when birds were exposed to contaminated poultry equipment at transport (15). The slaughter of chickens from Campylobacter-positive farms was associated with the contamination of chicken meat products $(11,13,14)$.

\section{Implications to human health}

Human Campylobacter infections have been linked to the consumption of contaminated poultry meat products (16-19). A study conducted in the United States has shown that ciprofloxacin-resistant Campylobacter infection can result in prolonged infections (19). More recently, a Canadian study found that human Campylobacter isolates are often genetically related to chicken isolates (20), but susceptibility data for human infections are limited and are currently not available for surveillance systems in Canada.

A previous U.S. risk assessment report (2000) has shown that chicken products contaminated with ciprofloxacin-resistant Campylobacter contribute to ciprofloxacin-resistant Campylobacter infections in humans (21). Consequently, good food safety and hygiene practices are more important than ever to ensure the reduction in transmission of resistant and susceptible Campylobacter from contaminated meat to people. This includes appropriate wrapping and placement of chicken in refrigerators, careful washing of surfaces and utensils that touch raw chicken, using different surfaces for preparing raw meat and vegetables/fruit, and thorough cooking (22). 


\section{Effect on industry policy response}

Recently, the Canadian poultry industry developed a policy to eliminate the preventive use of antimicrobials considered of very high importance to human medicine; these include third generation cephalosporin and fluoroquinolone antimicrobials (23). This policy took effect in May 2014 for broilers and will take effect in May 2015 for broiler breeders and turkeys (23). A one-year extension of the implementation of this policy will allow the industry to inform key stakeholders of this change.

\section{Effect on surveillance}

In April 2013, CIPARS initiated surveillance of antimicrobial use and antimicrobial resistance at the broiler farm level. This new surveillance component will help investigate the relationships between antimicrobial use and resistance and will track the potential impact of recent industry policy changes on the occurrence of resistance in Campylobacter and other enteric pathogens from poultry.

\section{Discussion and conclusion}

CIPARS documented that ciprofloxacin-resistant Campylobacter in retail chicken occurs across the country; levels in Western Canada have been dropping, but the previously low to absent levels in Eastern Canada have been rising.

Antimicrobial resistance risk management has no quick fix; patterns of antimicrobial use can take a long time to change and patterns of resistance can also take a long time to disappear. Despite the progress that has been made, CIPARS continues to detect ciprofloxacin-resistant Campylobacter in retail chicken in Canada. It is still unclear how resistance to fluoroquinolones emerged in Campylobacter from broilers in Canada, and if and how it spread from the Western to Central and Eastern regions, or if it emerged independently.

The driver of fluoroquinolone use in this sector also remains unclear. The Veterinary Drugs Directorate established a policy recommending against the extra-label use of Category I antimicrobial drugs in foodproducing animals (10); however, this lies under the purview of practice of veterinary medicine to enforce. Initial data from the farm program suggest that limited extra-label use of fluoroquinolones is occurring in Canadian broiler chicken flocks. CIPARS will continue to monitor farm drug usage and reasons for use (i.e., prophylactic or therapeutic) and to evaluate associations between antimicrobial use and resistance.

CIPARS previously identified gaps in the surveillance of Campylobacter and antimicrobial use practices in Canada. As a result, surveillance of antimicrobial use and resistance at the broiler farm level in Canada was initiated in April 2013; these new data are being used to investigate the relationships between antimicrobial use and resistance as well as the impact of recent policy changes. In addition, CIPARS is currently determining the best approach to carry out AMR testing of human Campylobacter infections to better understand the public health impact of exposure to ciprofloxacin-resistant Campylobacter through retail chicken meat and other sources.

CIPARS will continue to monitor trends in antimicrobial use and resistance following industry's intervention eliminating the preventive use of Category I antimicrobials (of very high importance to human medicine). However, by following good food preparation and hygiene practices, Canadians can reduce the risks of developing a Campylobacter infection from retail chicken.

\section{Acknowledgements}

The authors would like to acknowledge Rita Finley, Dr. Danielle Daignault and the staff at the Laboratory for Foodborne Zoonoses, St. Hyacinthe, Québec; Nicol Janecko and the CIPARS retail field staff; Dr. J.T. McClure/collaborators at University of Prince Edward Island; and Centre for Coastal Health in British 
Columbia. The authors would like to thank the Canadian Food Inspection Agency and Health Canada's Veterinary Drugs Directorate for reviewing the manuscript.

\section{Funding}

None.

\section{Conflict of interest}

None.

\section{References}

(1) Thomas MK, Murray R, on behalf of the Canadian Burden of Food-borne Illness Estimates Working Group. Estimating the burden of food-borne illness in Canada. CCDR. 2014 40-14; 299-http://www.phacaspc.gc.ca/publicat/ccdr-rmtc/14vol40/dr-rm40-14/dr-rm40-14-comm-eng.php

(2) Thomas MK, Murray R, Flockhart L, Pintar K, Pollari F, Fazil A, et al. Estimates of the burden of foodborne illness in Canada for 30 specified pathogens and unspecified agents, circa 2006. Foodborne Pathog Dis. 2013; 10(7):639-48.

(3) Olson C, Ethelberg S, Van Pelt W, Tauxe R. Epidemiology of Campylobacter infections in industrialized nations. In: Nachamkin I, Szymanski CM, Blaser MJ, editors. Campylobacter. 3rd ed. Washington: American Society for Microbiology Press; 2008.

(4) Blondel-Hill E, Fryters S. Bugs and Drugs: An Antimicrobial/Infectious Diseases Reference. Edmonton: Alberta Health Services; 2012.

(5) Deckert AE, Reid-Smith RJ, Tamblyn SE, Morrell L, Seliske P, Jamieson FB, Irwin R, Dewey CE, Boerlin P, McEwen SA. Antimicrobial resistance and antimicrobial use associated with laboratory-confirmed cases of Campylobacter in two health units in Ontario. Can J Infect Dis Med Microbiol. 2013 Spring; 24(1):e16-e21.

(6) Dryden MS, Gabb RJ, Wright SK. Empirical treatment of severe acute community-acquired gastroenteritis with ciprofloxacin.Clin Infect Dis. 1996; 22:1019-25. DOI: 10.1093/clinids/22.6.1019

(7) Food and Agriculture Organization of the United Nations, World Health Organizaton, World Organisation for Animal Health. Joint FAO/WHO/OIE Expert Meeting on Critically Important Antimicrobials. Report of the FAO/WHO/OIE Expert Meeting, FAO, Rome, Italy, 26-30 November 20017. http://www.who.int/foodborne_disease/resources/Report_CIA_Meeting.pdf

(8) Government of Canada [web page]. Health Canada, Veterinary Drugs Directorate. Categorization of antimicrobial drugs based on importance in human medicine. 2009 Apr. http://www.hc-sc.gc.ca/dhpmps/vet/antimicrob/amr_ram_hum-med-rev-eng.php

(9) Hofacre CL, Fricke JA, Inglis T. Antimicrobial drug use in poultry. In: Giguere S, Prescott JF, Dowling PM, editors. Antimicrobial Therapy in Veterinary Medicine. 5th ed. John Wiley and Sons. Ames, lowa; 2013. p. 569-87.

(10) Government of Canada [web page]. Health Canada, Veterinary Drug Directorate. Policy on extra-label drug use (ELDU) in food producing animals. 2008 Aug. http://www.hc-sc.gc.ca/dhp-mps/vet/label-etiquet/pol_eldu-umddeeng.php

(11) Public Health Agency of Canada (PHAC). Canadian Integrated Program for Antimicrobial Resistance Surveillance (CIPARS) 2011-Antimicrobial Resistance Short Report. Guelph, ON: PHAC; 2012. http://publications.gc.ca/collections/collection_2013/aspc-phac/HP2-4-2-2011-eng.pdf

(12) Agunos A, Léger D, Avery BP, Parmley EJ, Deckert A, Carson CA, Dutil L. Ciprofloxacin resistant Campylobacter spp. in retail chicken, western Canada. Emerg Infect Dis. 2013 Jul; 19(7):1121-4. doi: 10.3201/eid1907.111417.

(13) Government of Canada [web page]. Public Health Agency of Canada, Canadian Integrated Program for Antimicrobial Resistance Surveillance (CIPARS). Surveillance Bulletin-Emergence of ciprofloxacin-resistant Campylobacter in retail chicken in British Columbia and Saskatchewan. 2011 Nov. http://www.phacaspc.gc.ca/cipars-picra/bulletin-eng.php 
(14) Avery BP, Parmley EJ, Reid-Smith RJ, Daignault D, Finley, RL, Irwin, RJ. Canadian Integrated Program for Antimicrobial Resistance Surveillance: Retail food highlights, 2003-2012. CCDR. 2014 Nov 6; 40S-2:35-44. http://www.phac-aspc.gc.ca/publicat/ccdr-rmtc/14vol40/dr-rm40-S2/index-eng.

(15) Agunos A, Waddell L, Leger D, Taboada E. A systematic review characterizing on-farm sources of Campylobacter spp. for broiler chickens. PLoS One. 2014 Aug 29; 9(8):e104905.

(16) Roux F, Sproston E, Rotariu O, Macrae M, Sheppard SK, Bessell P, et al. Elucidating the aetiology of human Campylobacter coli infections. PLoS One. 2013 May 29; 8(5):e64504.

(17) Strachan NJ, Gormley FJ, Rotariu O, Ogden ID, Miller G, Dunn GM, et al. Attribution of Campylobacter infections in northeast Scotland to specific sources by use of multilocus sequence typing. J Infect Dis. 2009 Apr 15; 199(8):1205-8.

(18) Friedman CR, Hoekstra RM, Samuel M, Marcus R, Bender J, Shiferaw B, et al. Risk factors for sporadic Campylobacter infection in the United States: A case-control study in FoodNet sites. Clin Infect Dis. 2004 Apr 15; 38 Suppl 3:S285-96.

(19) Nelson JM, Smith KE, Vugia DJ, Rabatsky-Ehr T, Segler SD, Kassenborg HD, et al. Prolonged diarrhea due to ciprofloxacin resistant Campylobacter infection. J Infect Dis. 2004 Sep 15; 190(6):1150-7.

(20) Levesque S, Frost E, Arbeit RD, Michaud S. Multilocus sequence typing of Campylobacter jejuni isolates from humans, chickens, raw milk, and environmental water in Québec, Canada. JClin Microbiol. 2008 Oct; 46(10):3404-11.

(21) United States Food and Drug Administration, Center for Veterinary Medicine. The human health impact of fluoroquinolone resistant Campylobacter attributed to the consumption of chicken. Washington: U.S. Food and Drug Administration, Center for Veterinary Medicine; 2000 Oct 18; updated 2001 Jan 5. http://www.fda.gov/downloads/AnimalVeterinary/SafetyHealth/AntimicrobialResistance/UCM083649.pdf

(22) Government of Canada [web page]. Campylobacter jejuni. 2012 Jan. http://healthycanadians.gc.ca/eatingnutrition/poisoning-intoxication/campylobacter-eng.php

(23) AgMedia Inc [web page]. Better Farming. Canada's chicken farmers plan to eliminate some antibiotic use by May 2014. 2013 Dec 10. http://www.betterfarming.com/online-news/canada\%E2\%80\%99s-chicken-farmersplan-eliminate-some-antibiotic-use-may-2014-54120 